\title{
Kinematic Characteristics of a Mei-yu Front Detected by the QuikSCAT Oceanic Winds
}

\author{
HSI-CHYI YeH \\ Department of Computer and Information Sciences, Aletheia University, Tamshui, Taipei, Taiwan \\ George TAI-Jen Chen \\ Department of Atmospheric Sciences, National Taiwan University, Taipei, Taiwan \\ W. Tiмотнy LiU \\ Jet Propulsion Laboratory, California Institute of Technology, Pasadena, California
}

(Manuscript received 25 April 2001, in final form 4 September 2001)

\begin{abstract}
Based on conventional surface observations and NASA Quick Scatterometer (QuikSCAT) data, a heavy rainfall event that occurred in the Taiwan mei-yu season was chosen to further study the kinematic characteristics of the accompanying surface front. With the help of the QuikSCAT oceanic surface winds, it was found that the location and propagation of a mei-yu front over the ocean to the east of Taiwan during 10-12 June 2000 are better represented by the frontal wind shift line, which was located approximately on the leading edge of the baroclinic zone.

The mesoscale system with cyclonic circulation embedded within the frontal zone was clearly shown in the wind field and kinematic parameters (horizontal divergence and vorticity) as well as satellite clouds and rainfall estimations. The conditional instability of the second kind (CISK) process was suggested to be responsible for the intensification of the mei-yu front and the frontal disturbance over the ocean. Under the influence of island topography over Taiwan and the mountains over southern China, the frontal wind shift line distorted and receded within the Taiwan Strait after the mei-yu front reached northern Taiwan. In the later period, the front moved southward faster to the area immediately east of Taiwan as compared to that over southwestern Taiwan and the Taiwan Strait due to earlier arrival of strong postfrontal northerly winds. The localized southwesterly jetlike feature was observed to the southeast of Taiwan and persisted until the arrival of the strong northerly winds. These localized phenomena were detected by the QuikSCAT oceanic winds.
\end{abstract}

\section{Introduction}

During the early summer rainy season of Taiwan (from mid-May to mid-June), the passage of frontal systems usually dominates the production of island rainfall, especially over northwestern Taiwan (Yeh and Chen 1998). About four to five surface frontal systems advance southeastward from southern China to Taiwan each year (Chen 1992), replacing southwesterly monsoon flow with postfrontal northeasterlies (Chen and $\mathrm{Li}$ 1995). The surface front is called the mei-yu front in Taiwan and China and the baiu front in Japan (Tao and Chen 1987).

For the climatic characteristics of the mei-yu fronts, Chen (1992) showed that most of the fronts passed Tai-

Corresponding author address: Dr. George Tai-Jen Chen, Department of Atmospheric Sciences, National Taiwan University, 61, Ln. 144, Sec. 4, Keelung Rd., Taipei 10772, Taiwan.

E-mail: george@atmos0.as.ntu.edu.tw wan and influenced the island weather, formed in the subtropical region of $20^{\circ}-35^{\circ} \mathrm{N}$ and $100^{\circ}-130^{\circ} \mathrm{E}$ with an average lifetime of 8 days. From satellite imagery, the fronts are usually accompanied by a synoptic-scale cloud band embedded within mesoscale convective systems, extending several thousand kilometers from southern Japan to southern China with an approximately eastwest orientation. The frontal precipitation covers a mesoscale range with a $700-\mathrm{km}$ width across the front (Chen 1992).

Synoptic-scale analyses associated with mei-yu fronts show that the front may be viewed as a combined midlatitude and tropical system (Chen 1992). Chen and Chang (1980) indicated that the front near Japan and over the East China Sea was similar to a midlatitude baroclinic front characterized by a strong horizontal temperature gradient and vertical tilt. Over southern China, the front possessed an equivalent barotropic warm core structure with a weak temperature gradient and strong low-level wind shear. Based on Taiwan Area 
Mesoscale Experiment (TAMEX) data, Chen et al. (1989), Trier et al. (1990), and Chen and Hui (1990, 1992) showed that over southern China the structure of the mei-yu front resembled a midlatitude cold front before seasonal transition in mid-June. After seasonal transition, with appreciable tropospheric warming over the China plain and the northward shift of the major baroclinic zone, the thermal contrast across the frontal zone greatly weakened (Chen 1993).

The structure and evolution of the subtropical cold front during the mei-yu season of Taiwan was examined through TAMEX mesoscale networks. The cold front was shallow and the postfrontal cold air was approximate $1 \mathrm{~km}$ deep in the region where the postfrontal northerlies were not obstructed by the island barrier (Chen et al. 1989; Trier et al. 1990; Chen and Hui 1990,1992$)$. To the south of $23^{\circ} \mathrm{N}$ in the vicinity of the southwestern coast of Taiwan, the depth of postfrontal cold air decreased to about $450 \mathrm{~m}$ (Chen and Hui 1990). The frontal leading edge resembled a density current (Trier et al. 1990; Chen and Hui 1990). For the evolution of a mei-yu front, Ray et al. (1991) showed that the increase in both convergence and deformation contributed to frontogenesis. Trier et al. (1990) suggested that the weakening of the mei-yu front over the Taiwan Strait during its progressive southward advancement was due to heat and moisture fluxes from the underlying ocean.

With complex island topography over Taiwan, the mountains frequently interacted with frontal systems to produce locally heavy rainfall (Kuo and Chen 1990). The Central Mountain Range (CMR) acts as a barrier to pre- and postfrontal airflows, and is also influential by virtue of its thermally driven local circulations (Trier et al. 1990; Chen and Li 1995). This obstacle split the mei-yu front into two segments as the front approached northern Taiwan. The movement of the eastern part along the coast of Taiwan was faster than that of the western one (Trier et al. 1990; Chen 1992; Chen and Li 1995). But the reason is still not well understood. The weather character of the frontal passage was considerably different on opposite sides of the island. Most of the west coast of Taiwan experienced a vigorous cold frontal passage with attendant convection and heavy rainfall (Trier et al. 1990; Yeh and Chen 1998). Over eastern Taiwan, convection was suppressed and only a small amount of rainfall was produced by frontal systems (Yeh and Chen 1998).

Previous results from the analyses of TAMEX data on mei-yu fronts have improved the understanding of the structure, evolution, and orographic effects on the mei-yu fronts over Taiwan. However, the location and propagation of mei-yu fronts over the ocean near Taiwan is difficult to determine with limited observations. With the launch of the National Aeronautics and Space Administration's (NASA) Quick Scatterometer (QuikSCAT) satellite in June 1999, the retrieved ocean surface winds are available. Based on QuikSCAT oceanic

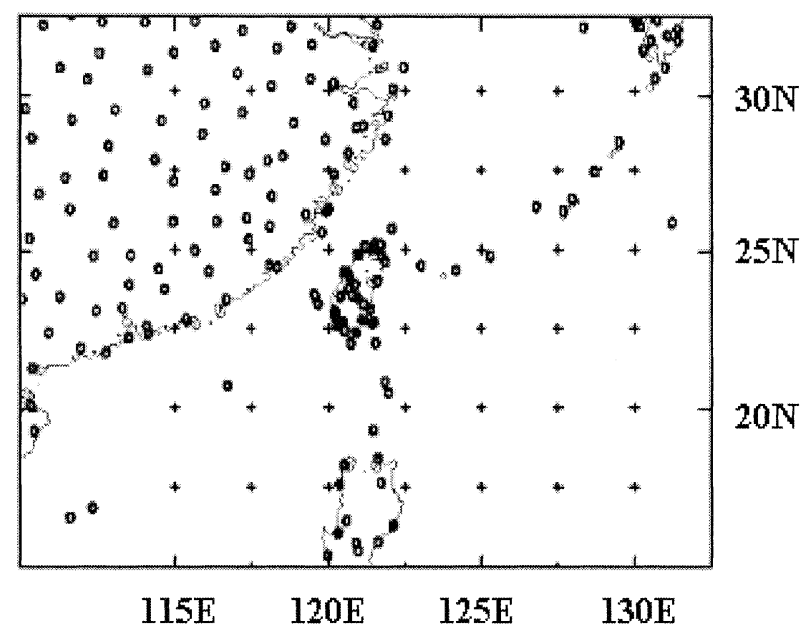

FIG. 1. Data locations for surface temperature analyses. Circles and plus signs represent locations of surface observations and NCEP grids, respectively.

winds, a heavy rainfall event over Taiwan associated with the passage of a mei-yu front during 11-12 June 2000 was chosen to further study the kinematic characteristics of a mei-yu front over the ocean near Taiwan.

\section{Data and analyses}

QuikSCAT surface winds over ocean and the surface observations over land were used to investigate the propagation of a mei-yu front over the western Pacific, southern China, and the vicinity of Taiwan. The surface observations from the Taiwan Central Weather Bureau (CWB) were used to reveal island weather associated with the passage of the surface frontal system during 11-12 June 2000. The Tropical Rainfall Measuring Mission (TRMM) rain estimations (Kummerow et al. 2000) were also used to link with the frontal system over the ocean and southern China.

Based on surface temperature observations over ocean and over land, spatial distribution of the surface temperature was objectively analyzed by an optimum interpolation method with the best weighting coefficient for nearby observations around the grid points (Schlatter et al. 1976). The first guesses of the objective analyses on the grid points were given by the regional mean of the observations. Data used in the interpolation scheme to obtain the surface temperature field are based on the combination of the surface observations and National Centers for Environmental Prediction (NCEP) grid data illustrated in Fig. 1 to resolve the temperature gradient associated with the mei-yu front.

The microwave scatterometer on QuikSCAT provides ocean surface wind vectors with a $25-\mathrm{km}$ spatial resolution over almost all of the global ocean daily, under cloudy and clear conditions, night and day (Graf et al. 1998). The wind vectors retrieved from QuikSCAT were found to exceed the accuracy specifications of $2 \mathrm{~m} \mathrm{~s}^{-1}$ 

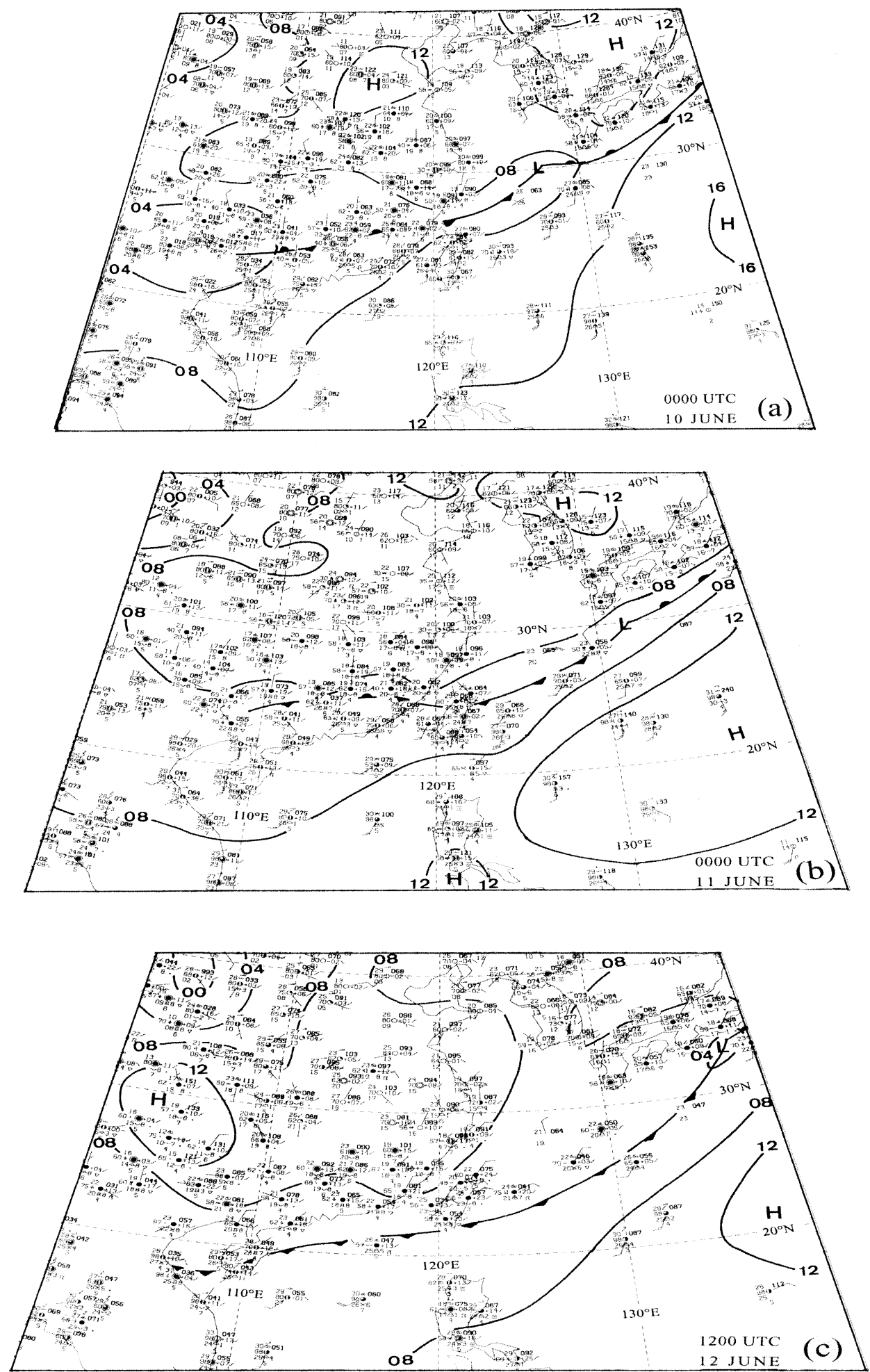

FIG. 2. Surface analyses at (a) 0000 UTC 10 Jun, (b) 0000 UTC 11 Jun, and (c) 1200 UTC 12 Jun 2000. Isobars analyzed at 4-hPa intervals. 

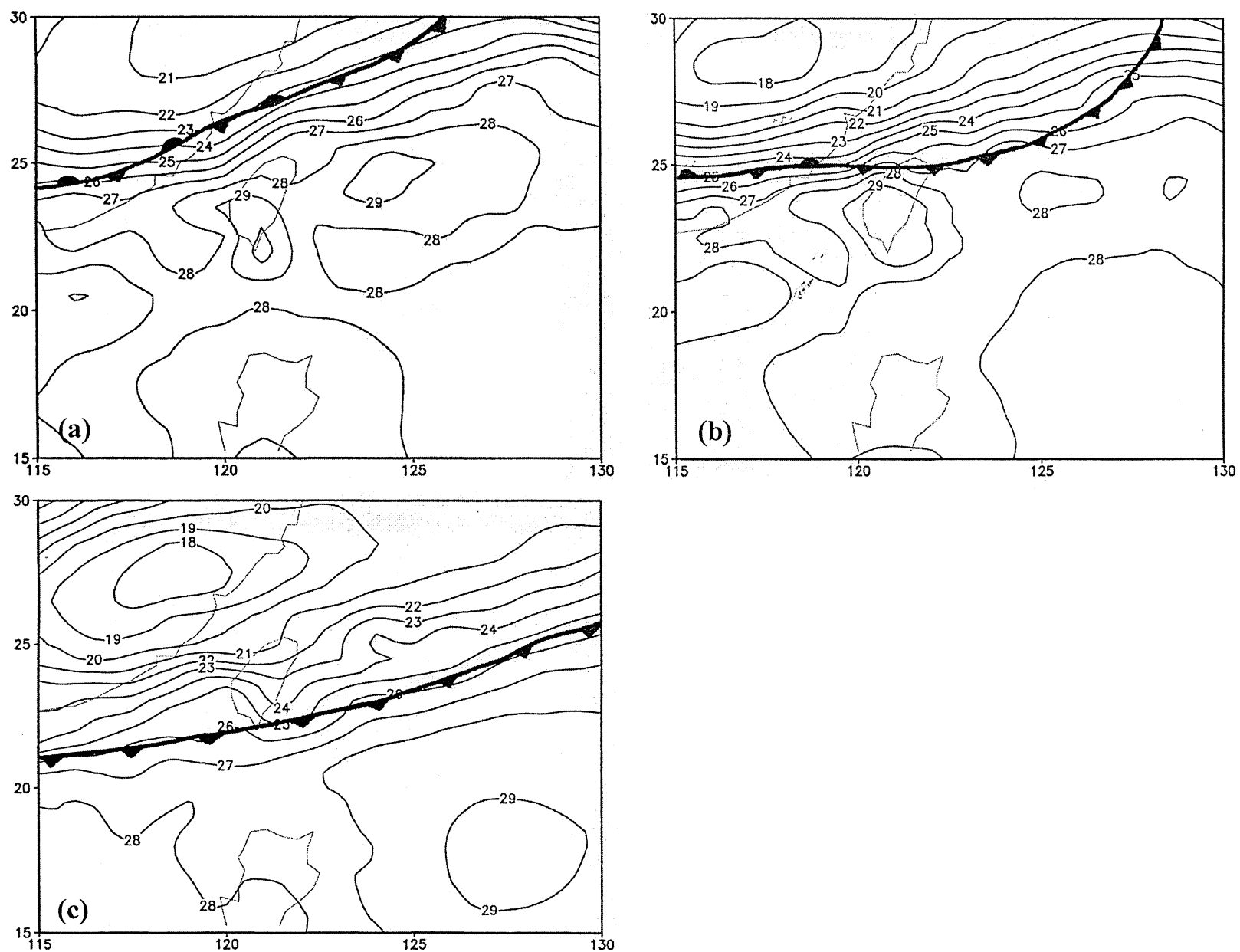

FIG. 3. Surface temperature distribution at (a) 0000 UTC 10 Jun, (b) 0000 UTC 11 Jun, and (c) 1200 UTC 12 Jun 2000. Isotherms analyzed at $1^{\circ} \mathrm{C}$ intervals. The surface front was a synoptically analyzed front as presented in Fig. 2.

or $10 \%$ in wind speed, and $20^{\circ}$ in direction, for a wind range of 3-30 $\mathrm{m} \mathrm{s}^{-1}$, and describe more detailed structures than any operational numerical weather prediction products (Liu et al. 2000). To have the QuikSCAT oceanic winds every $12 \mathrm{~h}$, at 0000 and $1200 \mathrm{UTC}$, the observations are objectively interpolated by the method of successive corrections to produce the data on a grid of $0.5^{\circ}$ latitude by $0.5^{\circ}$ longitude resolution (Liu et al. 1998).

To incorporate the information of QuikSCAT ocean surface winds over the coastal regions, the surface winds over land were also obtained objectively by the optimum interpolation method. Over the ocean, the QuikSCAT winds were used for all the analyses and computations. The vorticity and divergence fields were calculated from the wind fields that combined the objectively analyzed surface winds over land with QuikSCAT ocean surface winds. The results of vorticity and divergence were also used to diagnose the associated weather system and weather pattern over the ocean, and Taiwan and vicinity.

\section{Synoptic situation and island weather}

Based on surface synoptic analyses, a mei-yu front (Fig. 2a) with a northeast-to-southwest orientation extended from southern Japan to southern China at 0000 UTC 10 June. The objectively analyzed surface temperature field (Fig. 3a) from surface observations and NCEP grid data (Fig. 1) showed a significant gradient associated with the frontal system. At 0000 UTC 11 June, this front (Fig. 2b) moved southward and passed through northern Taiwan with an increase in the surface temperature gradient (Fig. 3b). Under the influence of the frontal system, the temperature decreased noticeably and a daily rainfall maximum greater than $100 \mathrm{~mm}$ (not shown) was observed over northern Taiwan, consistent with the convective clouds embedded within the meiyu frontal cloud band (Figs. 4a and 4b).

One day later, the surface front passed through central Taiwan and moved to the southern tip of the island at 1200 UTC 12 June (Fig. 2c). The major frontal cloud band passed through Taiwan (Figs. $4 \mathrm{c}$ and $4 \mathrm{~d}$ ). The daily 

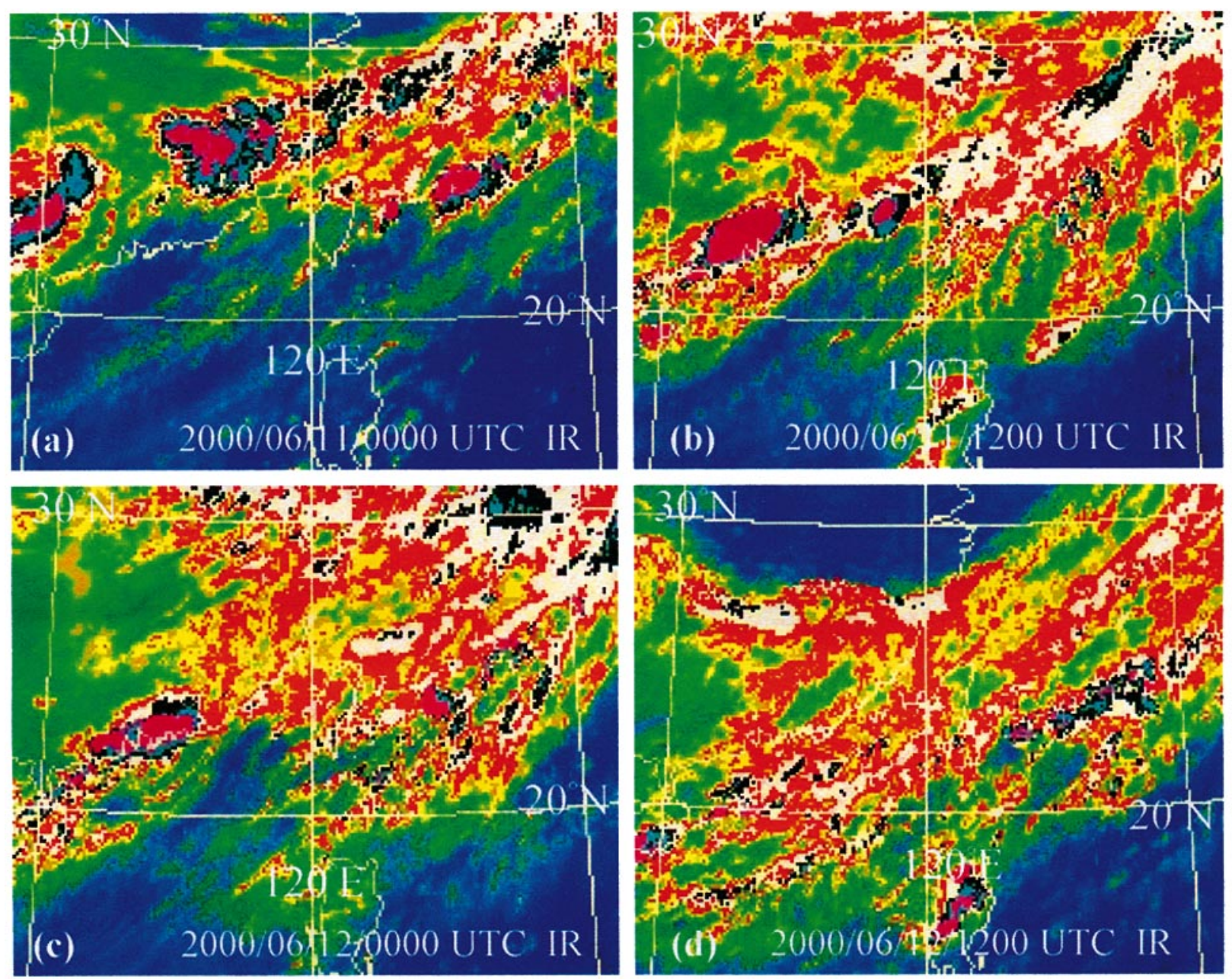

FIG. 4. GMS infrared images at (a) 0000 UTC 11 Jun, (b) 1200 UTC 11 Jun, (c) 0000 UTC 12 Jun, and (d) 1200 UTC 12 Jun 2000.

rainfall maximum ( $>100 \mathrm{~mm} \mathrm{day}^{-1}$; not shown) was observed over northern Taiwan and the area to the west of the CMR. Over eastern Taiwan, the rainfall amount associated with the frontal passage was small. As was also found by Yeh and Chen (1998), only a small amount of rainfall over the lee side of the CMR was produced by the frontal systems under the influence of the prevailing southwesterly monsoon flow during the early summer rainy season of Taiwan. In addition, the surface temperature (Fig. 3c) decreased dramatically $\left(\sim 4^{\circ}-6^{\circ} \mathrm{C}\right)$ over Taiwan as the frontal passage occurred during 1112 June. This is similar to the passage of a midlatitude cold front with a significant temperature drop. The comparable case of the mei-yu front was also observed during TAMEX (Trier et al. 1990). It is interesting to note that the leading edge of the maximum temperature gradient moved southward much faster to the east than to the west of Taiwan (Fig. 3c). From the TAMEX studies (Trier et al. 1990; Chen 1992; Chen et al. 1995), the frontal system always was obstructed and split by the island obstacle. The frontal position as revealed by the synoptic analysis apparently did not capture this mesoscale feature due to the Taiwan topographical effect.

Although the southward propagation of the mei-yu front was properly shown in the surface synoptic analyses, the location of the surface front over the ocean was still uncertain under limited observations. In addition, the effect of the island topography over Taiwan on the surface frontal system was also not reflected in the synoptic surface analyses.

\section{Kinematic properties of a mei-yu front}

Using the QuikSCAT winds during 10-12 June 2000, the location and propagation of the wind shift line over the ocean can be easily analyzed. The wind shift line over the ocean was defined as the boundary between the southerly wind component and nonsoutherly wind component. Over land (southern China and Taiwan) and within the Taiwan Strait, the surface wind speeds and wind directions were strongly influenced by topography during the passage of the surface front in this case. 

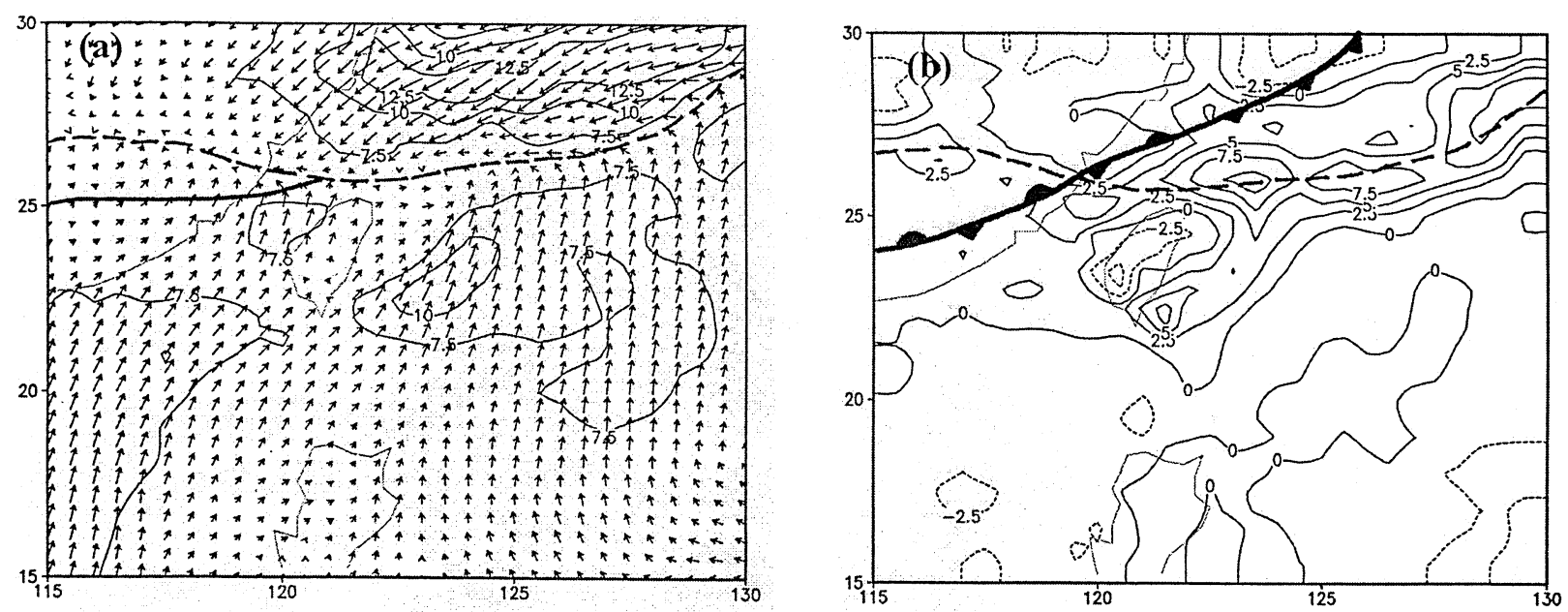

$\overrightarrow{10}$

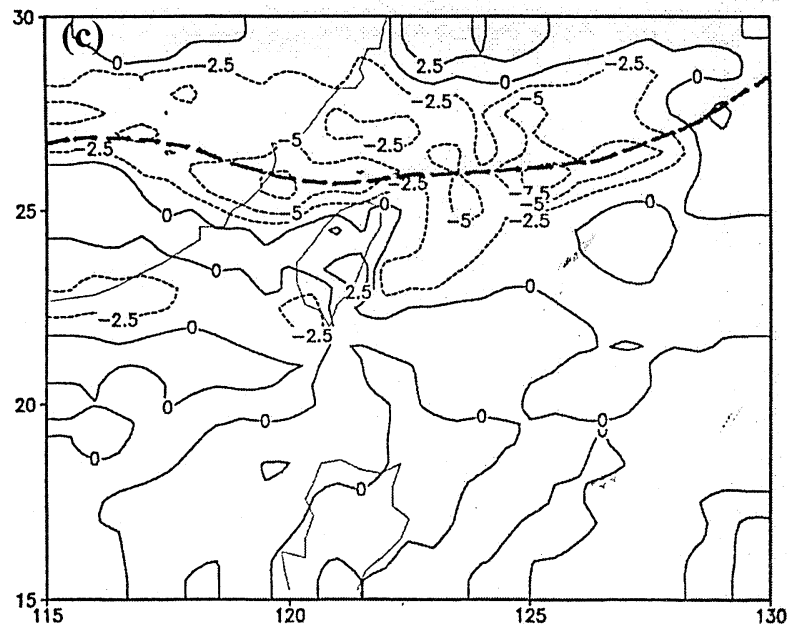

FIG. 5. (a) Objectively analyzed surface wind vectors and isotaches analyzed at $2.5 \mathrm{~m} \mathrm{~s}^{-1}$ intervals, (b) vorticity analyzed at $2.5 \times 10^{-5}$ $\mathrm{s}^{-1}$ intervals, and (c) horizontal divergence analyzed at $2.5 \times 10^{-5} \mathrm{~s}^{-1}$ intervals at 0000 UTC 10 Jun 2000. The dashed line is the frontal wind shift line and the solid line in (a) is the adjusted surface front. The surface front in (b) was the synoptically analyzed front as presented in Fig. 2.

Therefore, the location and propagation of the surface front may not be determined only by the frontal wind shift line. The location of the mei-yu front over southern China, Taiwan, and its immediate vicinity was based on the surface synoptic analysis adjusted by the area of maximum surface temperature gradient.

The surface winds at 0000 UTC 10 June (Fig. 5a) revealed that the wind shift line was clearly located over ocean to the north and northeast of Taiwan and over southern China. Over the ocean, the wind shift line was much closer to the leading edge of the baroclinic zone revealed by the surface temperature field (Fig. 3a) as compared with that analyzed synoptically (Figs. 2a and $5 b)$. The areas of the maximum cyclonic vorticity (Fig. $5 \mathrm{~b}$ ) and the maximum horizontal convergence (Fig. 5c) were also distributed along the wind shift line. Thus, the location and propagation of the mei-yu front over the ocean can be represented by the wind shift line. In other words, the surface frontal zone as revealed by the synoptic analysis over the ocean can be improved substantially by high-resolution QuikSCAT winds.

At this time, the surface front over southern China was located to the south of the frontal wind shift line (Fig. 5a). Significant rainfall was observed to the north of the surface front over the ocean based on TRMM rainfall estimations from 2115 UTC 9 June to 0149 UTC 10 June (Fig. 6a), in the same area where the frontal cloud band and the embedded convective systems actively developed as revealed by Geostationary Meteorological Satellite (GMS) infrared images (not shown). Over the northern Taiwan Strait, the rainfall maximum occurred over the area of maximum horizontal convergence and cyclonic vorticity (Figs. $5 \mathrm{~b}$ and $5 \mathrm{c}$ ). Within the frontal zone, the wavelike mesoscale structure was also apparent in the vorticity field with a maximum value of $1.0 \times 10^{-4} \mathrm{~s}^{-1}$ (Fig. 5b).

In addition, a couplet of anticyclonic and cyclonic vorticity centers (Fig. 5b) existed over southern Taiwan 

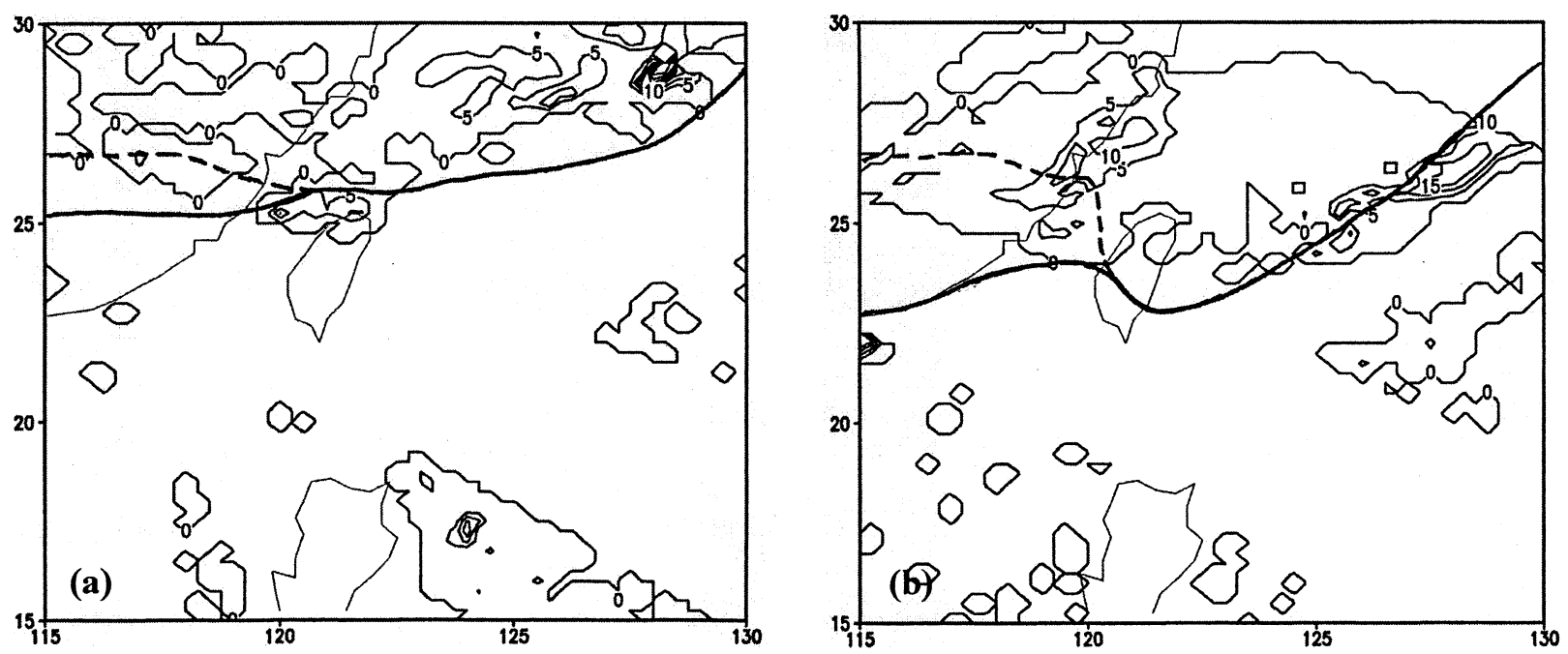

FIG. 6. TRMM rainfall (mm) analyzed at 5-mm intervals during (a) 2115 UTC 9 Jun-0149 UTC 10 Jun and (b) 2200 UTC 11 Jun-0100 UTC 12 Jun 2000. The dashed and solid lines represent the frontal wind shift line and the surface front, respectively.

across the Central Mountain Range. To reveal the mesoscale feature in the wind field associated with this couplet of vorticity centers, the bandpass filter (Maddox 1980) was applied to the wind field over Taiwan and the nearby ocean. The results (Fig. 7a) of bandpass winds showed that the anticyclonic vortex was related to the windward anticyclonic vorticity and the cyclonic vortex to the leeside cyclonic vorticity (Fig. 7a). The windward mesoscale ridge and leeside mesolow were revealed by the surface pressure analyses (not shown). With the in- crease of the prevailing southwesterly flow, the windward mesoscale ridge (leeside mesolow) with significant anticyclonic (cyclonic) circulation (Fig. 7) still occurred there at 0000 UTC 11 June. The windward ridge was caused by lifting and positive density anomalies aloft as the low-level air was pushed up along the windward slope (Smith 1982). The formation of the leeside mesolow was possibly due to the subsidence warming coupled with the vertical vortex stretching process (Kuo and Chen 1990; Chen and Li 1995; Sun et al. 1991; Lin et al. 1992).
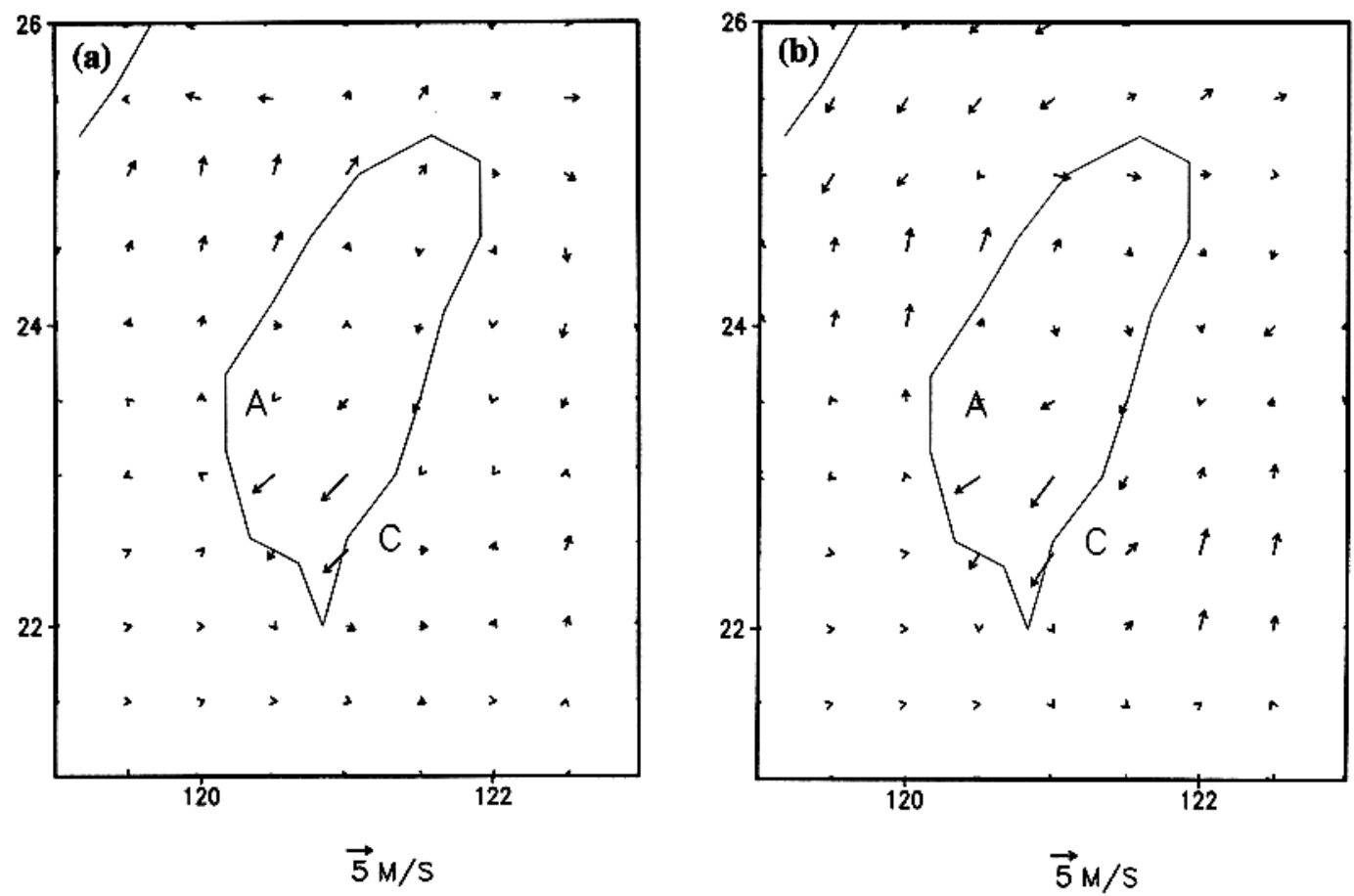

FIG. 7. Bandpass winds at (a) 0000 UTC 10 Jun and (b) 0000 UTC 11 Jun 2000. 


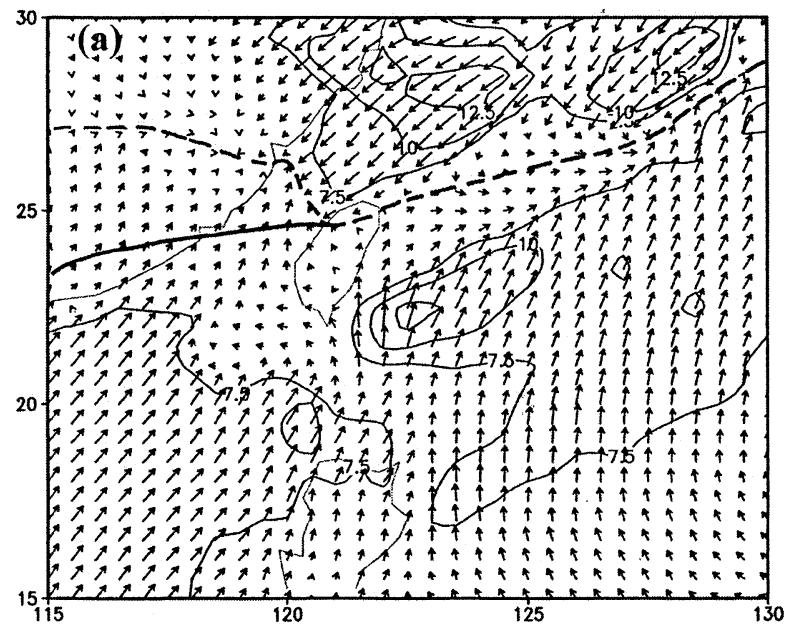

$\overrightarrow{10}$

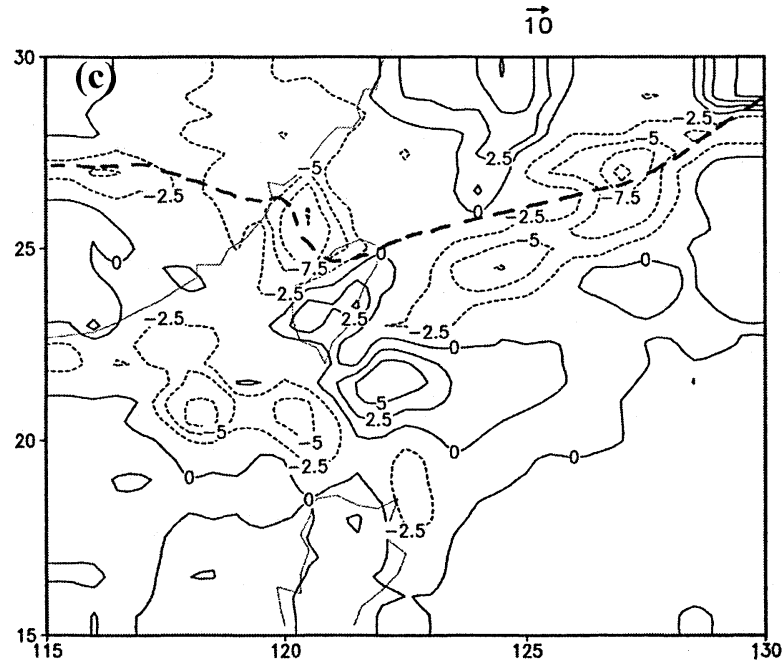

FIG. 8. As in Fig. 5 except for 1200 UTC 11 Jun 2000.

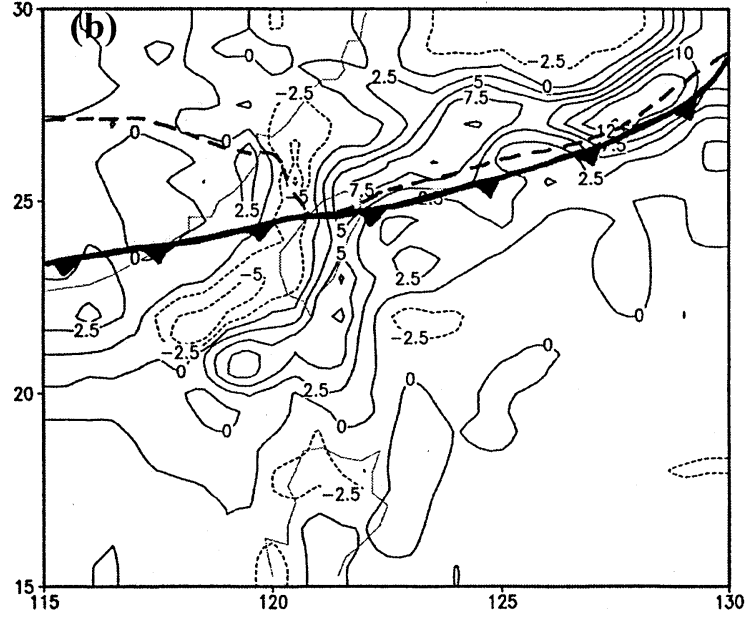

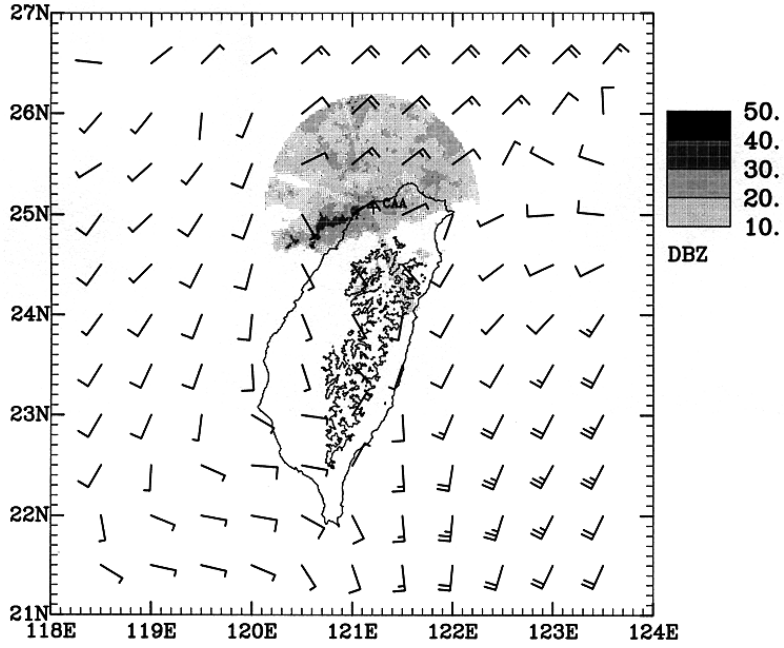

FIG. 9. Winds $\left(\mathrm{m} \mathrm{s}^{-1}\right)$ at surface superimposed with CAA radar reflectivity at 1200 UTC 11 Jun 2000 . The full barb and half barb represent 5 and $2.5 \mathrm{~m} \mathrm{~s}^{-1}$, respectively. The terrain contour of 1500 $\mathrm{m}$ is indicated.
Moreover, the strong southwesterly winds $\left(>10 \mathrm{~m} \mathrm{~s}^{-1}\right)$ with a jetlike structure occurred to the southeast of Taiwan over the ocean (Fig. 5a).

At 1200 UTC 11 June, the frontal wind shift line (Fig. 8a) over the ocean to the east of Taiwan moved southward slowly with a northeast-to-southwest orientation. It was close to the leading edge of the maximum temperature gradient (not shown). Over southern China, the wind shift line receded. It may be affected by the mountains over southern China as suggested by Chen and Hui (1990). Over the northern Taiwan Strait, the wind shift line was distorted by the island obstacle and changed its orientation to a northwest-to-southeast direction. It was associated with the increase of southwesterly winds over the northern Taiwan Strait and the intrusion of postfrontal northeasterlies along the northern coast of Taiwan. The synoptic surface analysis did not capture this mesoscale phenomenon locally. The maximum anticyclonic vorticity (Fig. 8b), instead of cyclonic vorticity (Fig. 5b), occurred over this localized wind shift line over the northern Taiwan Strait. This was 

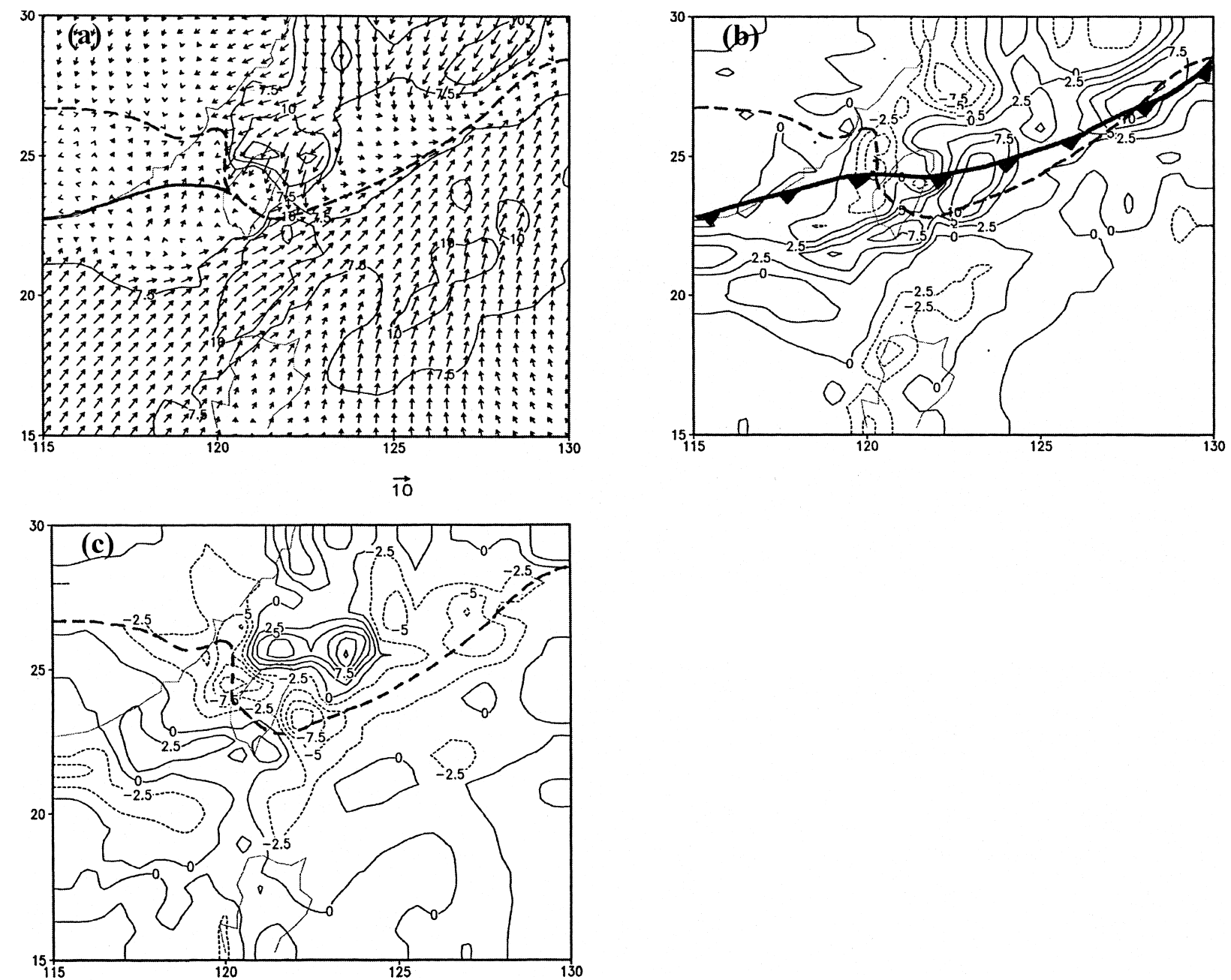

FIG. 10. As in Fig. 5 except for 0000 UTC 12 Jun 2000.

the area where the horizontal convergence (Fig. 8c) reached a maximum value of $-1.25 \times 10^{-4} \mathrm{~s}^{-1}$ and convective clouds also prevailed (Fig. 4b).

Over the area along and off the northwestern coast of Taiwan, the offshore flows, the southwesterlies, and the postfrontal northeasterlies (Figs. 8a and 9) tended to converge and to produce the convergence zone (Fig. $8 \mathrm{c}$ ). This was also the area where convection was active as shown by Civil Aeronautical Administration (CAA) radar echoes (Fig. 9). The area with daily rainfall greater than $50 \mathrm{~mm}$ (not shown) occurred over northwestern Taiwan where the convective systems developed intermittently within the convergence zone (Fig. 8c) apparently due to the frontal and topographical forcing. Near the southwestern coast of Taiwan, the prevailing southwesterlies decelerated and deflected (Fig. 8a) due to the orographic blocking (Trier et al. 1990; Li and Chen 1998). The deflected and returned surface winds off the southwestern coast of Taiwan met the prevailing southwesterly flow to form a couplet center of anticyclonic and cyclonic vorticity over the ocean (Fig. 8b). Over the ocean to the southeast of Taiwan, the horizontal divergence (Fig. 8c) was associated with the strong wind speed divergence of the southwesterlies over the same area. The localized jetlike feature was still observed to the southeast of Taiwan with a maximum wind speed of $12.5 \mathrm{~m} \mathrm{~s}^{-1}$. The occurrence of this localized strong southwesterly flow suggests a local forcing related to the Taiwan topography.

At 0000 UTC 12 June, the mei-yu front over the ocean was also better analyzed by the wind shift line as compared with the synoptically analyzed surface front. Similar to the previous period, the wind shift line over southern China was lagged behind the surface front. Part of the frontal wind shift line (Fig. 10a) to the immediate east of Taiwan significantly advanced southward to southeastern Taiwan especially along the eastern coast after the arrival of strong postfrontal northerly flow. In the surface synoptic analysis, the influence of the island obstacle on the airflow was not resolved. Thus, the northwest-southeast-oriented surface front over south- 

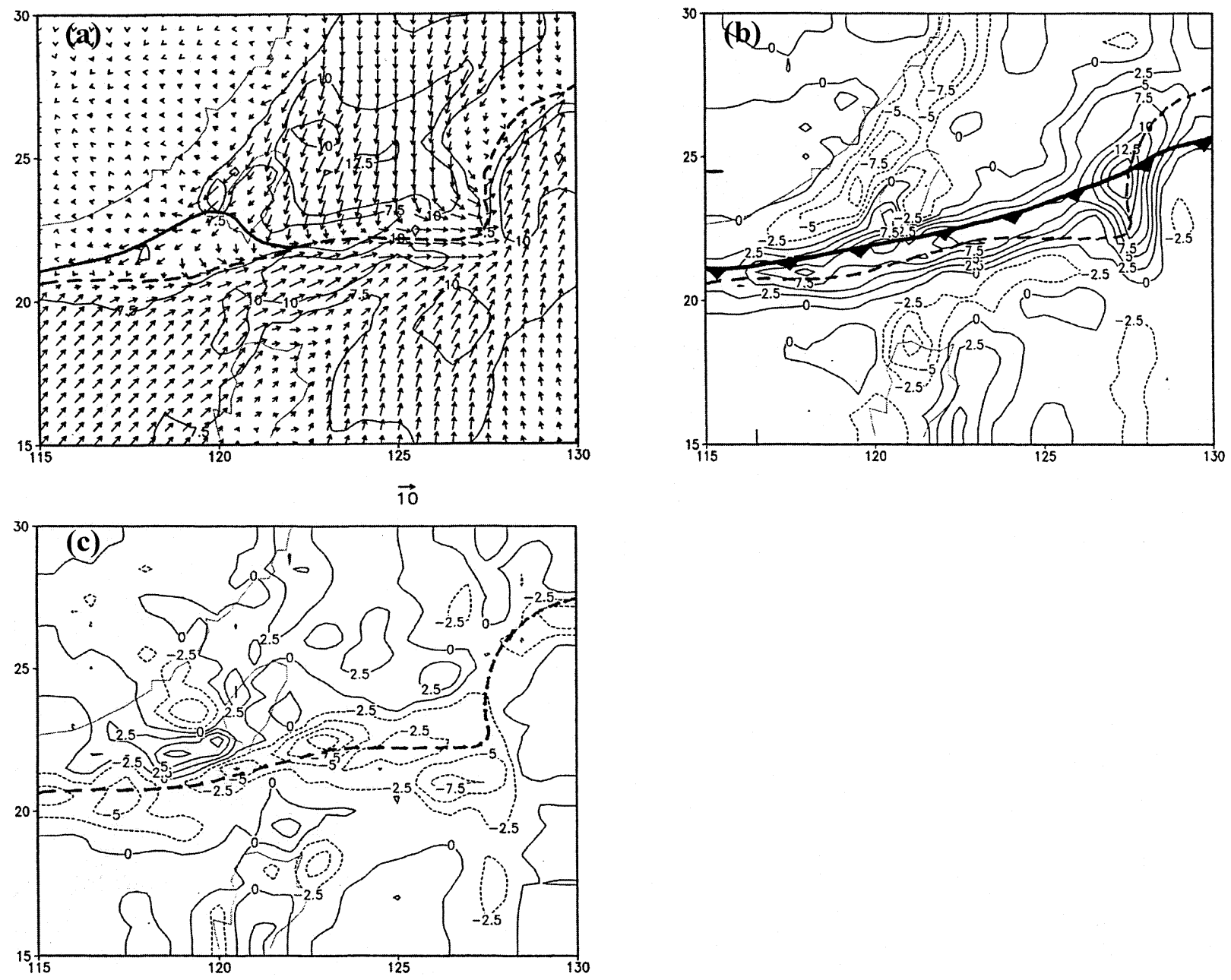

FIG. 11. As in Fig. 5 except for 1200 UTC 12 Jun 2000.

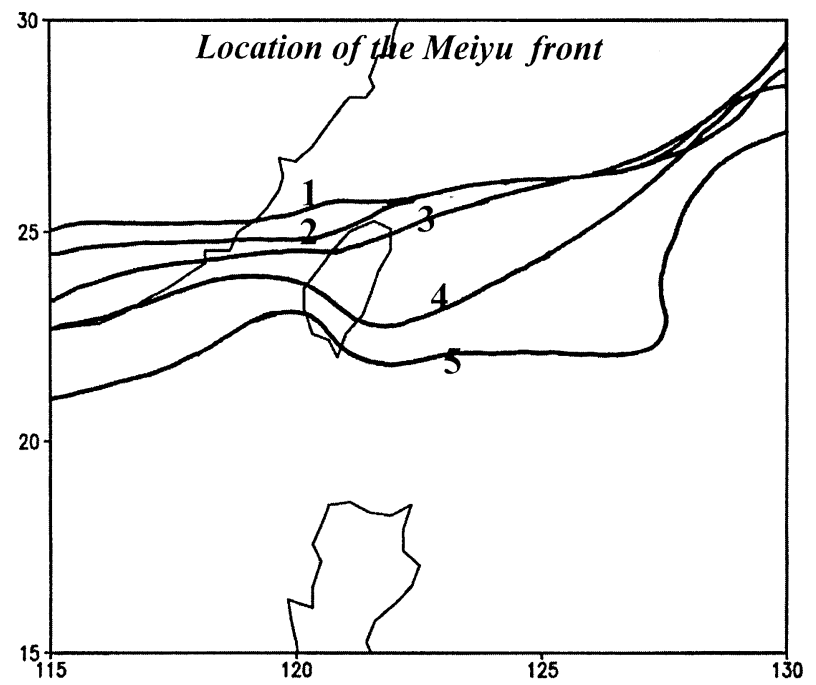

FIG. 12. Location of the mei-yu front at 0000 UTC 10 Jun (1), 0000 UTC 11 Jun (2), 1200 UTC 11 Jun (3), 0000 UTC 12 Jun (4), and 1200 UTC 12 Jun (5). ern Taiwan (Fig. 10a) was synoptically analyzed to pass directly through central Taiwan (Fig. 10b).

At this time, organized convection was observed over the area of maximum convergence and maximum cyclonic vorticity along the mei-yu front over the ocean near $25^{\circ} \mathrm{N}, 128^{\circ} \mathrm{E}$ (Fig. 4c). This was also the area where TRMM rainfall estimation reached a local maximum (Fig. 6b). Another area of maximum cyclonic vorticity (Fig. 10b) occurred along the mei-yu front over the ocean to the immediate east of Taiwan and was roughly collocated with the area of the horizontal convergence maximum (Fig. 10c). Only some scattered convection was observed over this area (Fig. 4c); thus, no rainfall was observed by TRMM (Fig. 6b). Within the Taiwan Strait, the wind shift line behind the surface front was still distorted and moved southward slowly. The horizontal convergence (Fig. 10c) located within the Taiwan Strait and along the wind shift line over western Taiwan was consistent with the satellite cloud observations (Fig. 4c) and TRMM rainfall estimation (Fig. 6b).

At 1200 UTC 12 June, the surface front continued to 
propagate southward especially over ocean as strong postfrontal north-to-northeasterly flow arrived (Fig. 11a). The strong northerly wind component over the ocean detected by the QuikSCAT data was not well captured by the limited conventional surface observations. The northwest-southeast-oriented surface front over southern Taiwan and the front over the Taiwan Strait and southern China coast moved southward slow1y. The surface front over southern Taiwan was supported by the surface temperature analysis (Fig. 3c) and the maximum cyclonic vorticity (Fig. 11b). Note that the locally distorted wind shift line over the northern Taiwan Strait during the previous period disappeared as the postfrontal northerlies arrived. Instead, a wind shift line over the northern South China Sea formed ahead of the surface front (Fig. 11a). Along the wind shift line over the ocean, the cyclonic vorticity (Fig. 11b) increased and collocated over the maximum of the convergence zone (Fig. 11c) where convection developed (Fig. 4d). Moreover, a cyclonic vorticity maximum (Fig. $11 \mathrm{~b})$ existed within the eastern part of the frontal system over the ocean, where convective clouds prevailed (Fig. $4 d$ ) and the orientation of the surface front was distorted. This mesoscale feature was not detected by the conventional surface analysis (Fig. 2c). As the cyclonic vorticity maximum increased to $>12.5 \times 10^{-5} \mathrm{~s}^{-1}$ along the mei-yu front, the Rossby radius of deformation was reduced to about $1000 \mathrm{~km}$. Thus, heating efficiency was enhanced by the latent heat release in the organized mesoscale convective systems embedded in the frontal cloud band with a horizontal scale of about 300-500 $\mathrm{km}$. Since the upper-level trough was located over southern China (not shown), it was possible that the CISK process was responsible for the intensification of the mei-yu front and the frontal disturbance in this case, as was also suggested by Chen and Chang (1980) and Cho and Chen (1995).

\section{Summary}

A case of a mei-yu front that caused heavy rainfall over northern and western Taiwan on 11-12 June 2000 was chosen to study the kinematic characteristics of the front. From the conventional synoptic surface analysis, a cold front in the midlatitudes will be located on the leading edge of the baroclinic zone with significant thermal contrast, wind shift, and cloud coverage. Over Taiwan and southern China, the structure of the mei-yu front was similar to a midlatitude cold front before seasonal transition in mid-June as analyzed by Chen et al. (1989), Trier et al. (1990), and Chen and Hui (1990, 1992). Compared to the surface front in the synoptic analysis, the objectively analyzed surface temperature field during 10-12 June (Fig. 2) shows the significant temperature gradient with respect to the frontal system and the dramatic temperature drop during the frontal passage, which suggested that the present frontal case possessed the character of a midlatitude cold front.
However, the location of the surface front was determined improperly due to the sparse surface observations over the ocean.

With the incorporation of the QuikSCAT ocean surface winds, the mei-yu front over the ocean is better represented by the frontal wind shift line. Under the influence of island topography over Taiwan, the wind shift line over Taiwan was distorted and split. The propagation of the surface front (Fig. 12) to the east of Taiwan moved faster than that over southwestern Taiwan and the Taiwan Strait, and was related to the earlier arrival of the strong northerly winds along the east coast and over the ocean to the east of Taiwan without the obstruction by the island topography (Figs. 10a and 11a). This phenomena was observed previously by synoptic and meoscale surface analysis without frontal details over the ocean near Taiwan (Chen 1992; Chen and Li 1995). Moreover, the localized southwesterly jetlike feature was observed over the ocean to the southeast of Taiwan and persisted until the arrival of the strong postfrontal northerly winds. The occurrence of this localized strong southwesterly flow suggests a local forcing related to the Taiwan topography.

The objectively analyzed surface winds and the calculated kinematic parameters (vorticity and horizontal divergence) as well as the satellite clouds and TRMM rainfall estimation revealed that the mesoscale system existed within the frontal zone over the ocean. This mesoscale feature cannot be resolved by conventional surface analyses due to the limited number of observations. In the later period, the cyclonic vorticity increased and collocated over the maximum convergence zone along the mei-yu front over the ocean where convection developed. Also, the centers of horizontal convergence and the cyclonic vorticity along the front over the ocean occurred over the same area where convection was also active. Taken together, this implies that the CISK process may be responsible for the intensification of the mei-yu front and the frontal disturbance.

Acknowledgments. This work was supported by the National Science Council in Taiwan under Grants NSC 89-2119-M-002-017 and NSC 90-2119-M-002-010 and was also supported in part by the Jet Propulsion Laboratory (JPL) through the scatterometer wind application project at the Naval Postgraduate School (NPS). The work of W. T. Liu was performed at JPL, California Institute of Technology, under contract with the National Aeronautics and Space Administration, and jointly supported by the QuikSCAT and TRMM projects. Xiaosu Xie helped to process the TRMM data. Discussion with and suggetions by Professor C. P. Chang of NPS were appreciated.

\section{REFERENCES}

Chen, G. T.-J., 1992: Mesoscale features observed in the Taiwan Meiyu season. J. Meteor. Soc. Japan, 70, 497-516. 
- , and C.-P. Chang, 1980: The structure and vorticity budget of an early summer monsoon trough (Mei-yu) over southeastern China and Japan. Mon. Wea. Rev., 108, 942-953.

Chen, Y.-L., 1993: Some synoptic-scale aspects of the surface fronts over southern China during TAMEX. Mon. Wea. Rev., 121, 5064.

, and N. B.-F. Hui, 1990: Analysis of a shallow front during the Taiwan Area Mesoscale Experiment. Mon. Wea. Rev., 118, 2649-2667.

and - 1992: Analysis of a relative dry front during the Taiwan Area Mesoscale Experiment. Mon. Wea. Rev., 120, 2442-2468.

- and J. Li, 1995: Characteristics of surface airflow and pressure patterns over the island of Taiwan during TAMEX. Mon. Wea. Rev., 123, 695-716.

, Y.-X. Zhang, and N. B.-F. Hui, 1989: Analysis of a surface front during the early summer rainy season over Taiwan. Mon. Wea. Rev., 117, 909-931.

Cho, H. R., and G. T. J. Chen, 1995: Mei-yu frontogenesis. J. Atmos. Sci., 52, 2109-2120.

Graf, J., C. Sasaki, C. Winn, W. T. Liu, W. Tsai, M. Freilich, and D. Long, 1998: NASA Scatterometer Experiment. Asta Astronaut., 43, 397-407.

Kummerow, C., and Coauthors, 2000: The status of the Tropical Rainfall Measuring Mission (TRMM) after two years in orbit. J. Appl. Meteor., 39, 1965-1982.

Kuo, Y.-H., and G. T.-J. Chen, 1990: The Taiwan Area Mesoscale Experiments: An overview. Bull. Amer. Meteor. Soc., 71, 488503

Li, J., and Y.-L. Chen, 1998: Barrier jets during TAMEX. Mon. Wea. Rev., 126, 959-971.

Lin, Y.-L., N.-L. Lin, and R. P. Weglarz, 1992: Numerical modeling studies of lee mesolows, mesovortices, and mesocyclones with application to the formation of Taiwan mesoscales. Meteor. Atmos. Phys., 49, 40-49.

Liu, W. T., W. Tang, and P. Polito, 1998: NASA scatterometer provides global ocean-surface wind fields with more structures than numerical weather prediction. Geophys. Res. Lett., 25, 761-764.

_, H. Hu, and S. Yueh, 2000: Interplay between wind and rain observed in Hurricane Floyd. Eos, Trans. Amer. Geophys. Union, 81, 253-257.

Maddox, R. A., 1980: An objective technique for separating macroscale and mesoscale features in meteorological data. Mon. Wea. Rev., 108, 1108-1121.

Ray, P. S., A. Robinson, and Y. Lin, 1991: Radar analysis of a TAMEX frontal system. Mon. Wea. Rev., 119, 2519-2539.

Schlatter, T. W., G. W. Branstator, and L. G. Thiel, 1976: Testing a global multivariate statistical objective analysis scheme with observed data. Mon. Wea. Rev., 104, 765-783.

Smith, R. B., 1982: Synoptic observations and theory of orographically disturbed wind and pressure. J. Atmos. Sci., 39, 348-364.

Sun, W.-Y., C.-C. Wu, and W.-R. Hsu, 1991: Numerical simulation of mesoscale circulation in Taiwan and surrounding area. Mon. Wea. Rev., 119, 2558-2573.

Tao, S., and L. Chen, 1987: A review of recent research on the east Asia summer monsoon in China. Monsoon Meteorology, C.-P. Chang and T. N. Krishnamurti, Eds., Oxford University Press, $60-92$.

Trier, S. B., D. B. Parsons, and T. J. Matejka, 1990: Observations of a subtropical cold front in a region of complex terrain. Mon. Wea. Rev., 118, 2449-2470.

Yeh, H.-C., and Y.-L. Chen, 1998: Characteristics of rainfall distribution over Taiwan during TAMEX. J. Appl. Meteor., 37, 14571469. 